\title{
Title: Ethical consequences in business decision process
}

\author{
Authors: Karaoulanis Andreas \\ MBA MScEng \\ andrekaraoul@gmail.com
}

\begin{abstract}
In this paper, the author tries to present the ethical dilemma in business decision process in Greece's frustrating economic environment. The author used the SSD decision approach in order to establish the theoretical background provided in terms of decision making and consequences.
\end{abstract}

Indexing terms/Key words: Decision making; Consequences; Ethical; Society; Uncertainty

Academic Discipline and Sub-Disciplines: Management; Business

Type (Method/ approach): Literacy analysis INTRODUCTION

In this paper, the author will try to present a company's decision making process in Greece's saturated market in order to close its factory in Greece, which is its home country, and open it in Bulgaria or another neighboring country, i.e. Skopje etc. due to less taxes and lower wages. The decision involves the fact that although the company will gain in financial terms, it will create a vast problem to the local society as about one hundred families will left unemployed not to mention a significant number of local suppliers of raw materials.

The yardstick for writing this paper was the Malmnas and Paulsson (2016) paper about decision problems and how to handle them, although several other sources were used.

\section{THE CASE COMPANY}

The author chose a company, which for now on will be called "the company" and which operates in the textile industry. Due to the economic recession of the last years, the company found itself to be in a stressful economic situation, in a saturated market, like the textile one.

The big majority of the company's employees are from the local city which is a small city of about 60,000 people. Also, it is important to mention that the local market is strongly bonded with the company in question in terms of providing the company's factory with raw material like fiber, yarn, fabric, dyes, chemicals and auxiliaries, something which underlines that the consequences to the local society from the closing of the factory are going to be extremely negative and the whole city will suffocate.

\section{UNCERTAINTY AVOIDANCE INDEX ${ }^{1}$}

In business, uncertainty springs from several sources. This is why we have demand uncertainty, supply uncertainty, competitor's uncertainty, "externalities" (Wernerfelt and Kamani, 1987, p.189).

According to Courtney et al., (1997, pp.75-78, cited in Karaoulanis , 2016), there are four levels of uncertainty:

$$
\begin{array}{cl}
\checkmark & \text { A clear- enough future } \\
\checkmark & \text { Alternate futures } \\
\checkmark & \text { A range of futures } \\
\checkmark & \text { True ambiguity }
\end{array}
$$

It is the author's prevalent idea that Greeks nowadays are facing the fourth option. Also, the combination of these two approaches are indicative of Greece's contemporary frustrated environment in social and business level. We need also, not to forget that in business too, decisions are been made by people who live in the same society and face the same frustrations in their everyday life, something which inevitably can have a vast impact in their decision making.

Greece's score on uncertainty avoidance index is 100 on the UAl (Hofstede, 2014 cited in Karaoulanis et al., 2015). Such a score is the biggest possible, maybe the highest in the world, indicating that the Greeks are not all comfortable in ambiguous situations and that they are fairly anxious and stressed about life (Karaoulanis et al., 2015).

The author underlines that, for the company's management, uncertainty is a strong influencer in decision making process in order to justify a decision for closing the factory in Greece and re- open it in a neighboring country. On the other hand, the local society which is the middle of the crisis vortex cannot afford such a solution which is going to be devastating. This

\footnotetext{
1 "Uncertainty avoidance can be defined as "the extent to which the members of a culture feel threatened by ambiguous or unknown situations. This feeling is, among other manifestations, expressed through nervous stress and in a need for predictability: a need for written and unwritten rules"'" (Hofstede et al., 2010, p.191, cited in Karaoulanis et al., 2015))
} 
feeling makes people much less assertive for the future and it can be a negative add on to the already high uncertainty avoidance index they express.

\section{THE TREE CONSTRUCTION}

According to Malmnas and Paulsson (2016), the first step in the representation of a decision problem is the three construction. In our case, the tree of the several possibilities concerning the decision in question is the following:

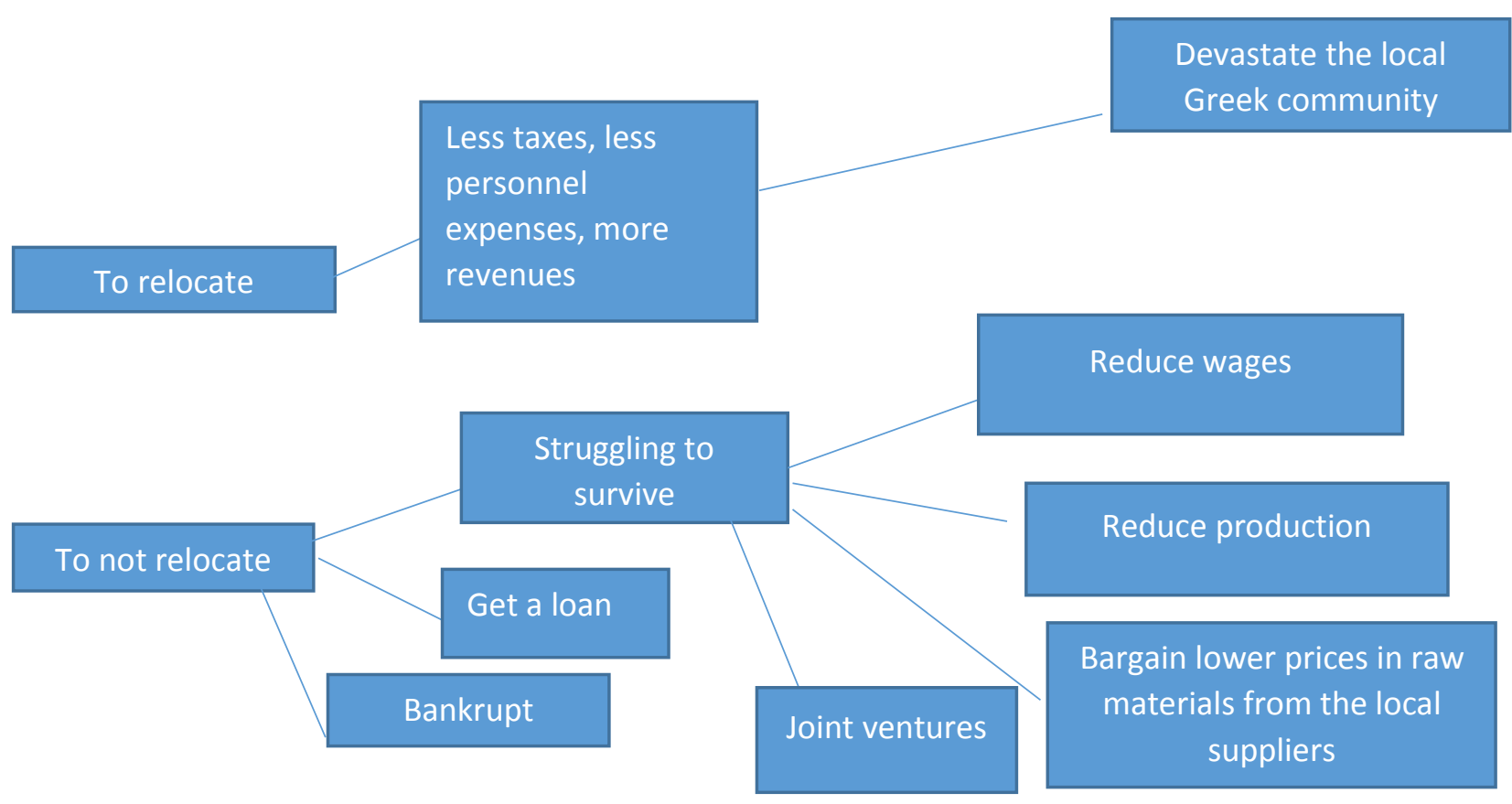

Figure 1: The decision making tree. The tree depicts the options offered in the decision making process of the company in question about relocating in a new country or stay in the mother one in order to overcome the recession problems.

As Malmnas and Paulsson (2016) indicated, in decision making problems, an option in order to be considered need to be evaluated in accordance with its consequences. In the above mentioned decision tree, we can see all the options involved in our decision problem as they are correlated to their consequences (decision nodes).

Also, (Malmnas; Paulsson, 2016), as we have a finite number of options which have a finite number of consequences (tree nodes), we are likely to use the SSD approach of the decision theory. So, after constructing our decision tree, the next step is to calculate the probability of the consequences, namely of each one of the tree nodes.

It is also important here to notice that a decision tree is only to help in decision making and does not give the answer to a decision problem itself. It helps in determining which alternative at any particular choice point will yield the best outcome given the information and alternatives presented in the tree's branches (Magee J.F., 1964).

\section{EVALUATING THE OPTIONS}

As we saw in the previous chapter, according to Malmnas and Paulsson (2016), after depicting the decision problem via the tree illustration, we need to evaluate the given options. "The first step in defining "risk" is determining which consequences it should include" (Fischhoff et al., 1984). The company found out that due to the given available options we have the following pros and cons:

\section{Option 1: To relocate}

Node 1: Less taxes, less personnel expenses, more revenues

If the company will choose to relocate, which means to close its factory in Greece and re- open it in a neighbour country, i.e. Bulgaria, the possibilities are that the company will have to pay significantly less taxes, it is going to buy raw materials in less price, while the wages of the personnel will be also significantly lower. This means that the company will going to have much less expenses, something which is going to help it get through the financial dead end that is facing now in Greece's frustrating environment.

Of course, before entering the new market, the company need to make a preliminary analysis of the domestic market conditions in order to find the more prospective country to enter. Such analysis need to be done in order to help the company to understand the current local customers' needs, to identify its local and foreign competitors and to understand whether it is going to address its products to a specific local market segment or to just enter the local furniture market (Best, 2014). . Either ways an analysis needed to be done. The company's strategists maybe need to follow a variance analysis pathway in order to determine the results of the metrics in use and to target the specific sources of potential problems in the company's marketing strategy (Best, 2014). 
Also, the company will need an initial budget as it is going to build a new plant in the new country, although a large part of that money will be acquired from the potential selling of the infrastructure left behind, not to mention that all the machinery will be transported to the new infrastructure, so that the budget will not be that big after all.

For the company, such a movement it will be like discovering a blue ocean ${ }^{2}$ or a new market out of nowhere. So, the bottom line in terms of risk is that this path is not very risky and also, very promising.

The long term result of such a movement will be that the company will have a chance of expanding, not only in the new country it is going to operate from now on, but abroad too.

As we can see from the above, the pros are very important and are going to weight very much in the final decision.

On the other hand, the local society will be devastated. After the closing of the factory, about one hundred families will going to be unemployed and in few days or months about $20-30 \%$ of the local companies which were the company's suppliers will need to terminate their business too. This is going to have a tremendous impact in the local society, which was struggling to survive in an uncertain environment and now will going to have to deal with a total disaster.

So, as we can see, if the company will decide to follow that direction, it will have to face the following dilemma : To relocate and thrive but destroy the local society upon which was going hand to hand the last twenty years, or to stay and fight with them in the common fight for survival.

It is the author's opinion that the dilemma has a strong ethical background, something which sometimes is quite different from the way the majority of the large multinationals deal with things as a vivid part of the capitalistic society we leave in.

\section{Option 2: To not relocate}

According to the decision tree, this option is followed by three tree nodes:

\section{Node 1: Struggle to survive}

If the company will follow this path, then nothing will change. The company will continue to address its products to the same market segment, following the already imposed market rules.

As we can easily see from the decision tree, such an option has many consequences. The company will have to make some movements in order to continue to operate under the crisis environment. Such movements can be the following:

$\checkmark$ Reduce wages: Although this is not a panacea, it is almost always the first measure a company can take in order to reduce expenses. Such approach will create big problems to the company's employees, but such problems are less important than unemployment.

$\checkmark \quad$ Reduce production: This will reduce cost too, but on the long run it will back fire as lower production will bring a smaller part of the market pie to the company, something will dramatically decrease its revenues.

$\checkmark$ Bargain lower prices in raw materials from the local suppliers: This is something which will eventually work. The local suppliers will understand the importance for the local society and themselves from the operation of the company, so they will be willing enough to reduce their prices, something which will reduce the production cost drastically enough for the company in question.

$\checkmark \quad$ Joint ventures: Finally, another option can be to join forces with another company in the same market segment. In that way it will increase its customers' base with almost no expenses. Such joint ventures sometimes need to be limited and to mainly focus on distribution in order to be able to minimize risks (Courtney et al., 1997, p.74).

Of course, the company can exercise a policy which will involve all these three paragons mentioned above simultaneously in order to get the needed result, which eventually is the cost reduction.

\section{Node 2: Get a loan}

This path is very difficult and usually gets nowhere because although getting a loan in order to invest is not a bad idea at all, getting a loan for just to survive is a very bad one. The company has limited revenues so needs to pay all its obligations like taxes, suppliers, wages etc. and all these expenses make it suffocate. A loan will give a temporary solution and even a deep breath, but if nothing will change when the time will come to pay the loan back, the company will be hopeless. This path looks like a dead end. The risk is extremely high and there are no potential good future in it in the long run, except if the economic conditions in the mother country (Greece) will alter in the near future.

\section{Node 3: Bankrupt}

This is the death of the company. Of course this is an out of the question option.

From the above mentioned evaluation of the options provided for the company in question, we understand that all options are risky. The company's strategists need to decide which road/ node to follow in order to face the minimum risk with the highest possible potential gain.

\footnotetext{
${ }^{2}$ blue oceans: represent the unknown market space (Kim and Mauborgne, 2004, cited in Karaoulanis,2015)
} 
There are some paragons which were discussed in the previous chapters which are decisive. One of them is the financial prospects of the relocation. It is absolutely sure that the company will gain a lot from relocation. This practise is something that after the Greek financial crisis a lot of companies followed.

Another decisive paragon is the ethical one. The company operates in this city for the last twenty years. The company based everything in the local society, from personnel, sales, supplies, so it has an ethical bond to the local society. If the company relocate, the local society will be devastated and an entire city will be the Detroit of Greece, although the comparison is not very suitable and analogous.

So, the company in question has to decide mainly about an ethical dilemma. To deal with the crisis basing its efforts on the local society and re- acquiring its socio- ethical grip on the local society for the common good, or to thrive by going abroad and devastate an entire city which was at the company's side making it profitable in the near past before the crisis outbreak?

I agree with Malmnas and Paulsson (2016), when they say that man relies more on intuition rather than rules when solving decision problems. But in our case we have to deal with a company. Usually in such cases intuition comes second following the metrics, thus calculations. I am not sure if this is the case in our paradigm as the company is very strongly bonded to the local society, something which will have a deep impact in the decision making process.

As the company has to survive, it need to base its efforts on the people who helped it on the beginning and gave it the profits needed in order to continue to operate for the last twenty years. It is the author's prevalent idea that when times are hard, leaving is not a panacea, while continue struggling and trust the people that were there for you in the past when needed will give you the solutions to get out of the dead end.

Also, cutting wages or reduce production is not a vital solution too. On the contrary retain wages as they are and talk to both people and the local society about the problem will give to all the people involved one way or another, which is the whole city in a way, to acquire the determination and the moral grip needed in order to do the extra mile and help the company in question to overcome its financial problems. There are some paradigms in Greece's society during the crisis where companies did not reduce wages or dismissed people but they retained their personnel and their wages, something which gave to these companies the competitive advantage needed to overcome their problems, as employees understood the sacrifice the company was making, so everybody was morally ready to do the extra mile. Today these companies thrive.

It is a good idea that the company can try to reach out the government in order to make it aware of the situation and the impact the problem will have to the local society. Also, thru the local mayor, the company can address the problem to the city's residents, even via an open forum under the auspices of the city's authorities in order to make everybody to understand that such crucial situation need everybody to be united and determined. In that way the company will have a very good chance to survive and to re- establish a strong bond with the local society. The benefits will be multiple.

\section{THE QRA ANSWERS}

In order to decide which the best possible path is, the company need to address some questions. According to Apostolakis (2004), in order to take the right decisions, the man in question has to face the following QRA questions:

1. What can possibly go wrong?

2. How likely is it to go wrong?

3. What are the consequences if something will go wrong?

In order to answer such questions, we need to understand that it is one thing to try to take a decision under normal circumstances and another under uncertainty. According to Kochenderfer M.J.(2015), many important problems need to be answered via a decision making process which is under uncertainty, something which means that we need to choose between actions by basing our decision on imperfect observations while expecting unknown outcomes. This is our case, as contemporary Greece's uncertainty creates a blur environment in terms of observations as companies tend to judge under vast, usually, economic pressure.

\section{PARAGONS INVOLVED IN DECISION MAKING AND THE TIME FACTOR}

Although the company maybe believe that the best way to solve its problems and escape to a better future is to relocate to a neighbouring country, as the calculus, in terms of expenses, indicate, the utility of such option is poor as it will going to create vast problems in the local society. So, in other words, there is a clear discrepancy in such occasions between behaviour and mathematical expectation (Menger, 1967).

According to Peter O. (2011), an important paragon in decision making problems is time. This is very important in our case, as we can easily understand that:

$\checkmark \quad$ If we could take the clock back some years before the crisis, the environment, in terms of uncertainty, would have been much better, something which not only would have impacted the decision making of our case, but maybe we wouldn't even had a case, if the market was not saturated and people had money to spend in consumerist goods. 
$\checkmark \quad$ It is important to notice that in such decision making process, the time denominator is very important as every day that is passing by can make the decision process more stressful, due to the expenses and costs accumulation on a daily basis, something which can have vast impact in the correct final decision.

So, we can easily understand that the time element in our decision equation is a very strong component which needs to be taken under vast consideration.

\section{UNCERTAINTY AND MORAL MOTIVATION}

According to Menger (1967), the company in question need to distinguish between two things:

$\checkmark$ Evaluation of uncertainty

$\checkmark \quad$ The risk, the company is willing to take as a result of that evaluation

But how clear such an evaluation can be under uncertainty and time pressure? Consequently, if we do not have a thorough and clear evaluation of uncertainty, as we can see depicted on the tree's branches, the risk, the company is willing to take as a result of the uncertainty evaluation, might be mistakenly large or small.

In order a company to take such decision, which will literary alter its future and the local society's future too, it must be motivated from something. This might be a positive, or even a negative motive. In our case, the negative motive is the uncertainty which springs from the financial crisis, while the positive motive will be the moral grip to local society which will be vastly affected from the decision.

According to Lincoln et al. (2011), there are four components involved in the ethical decision making process:

$\checkmark \quad$ Moral sensitivity (moral awareness): is an individual's ability to understand that a situation involves a moral issue (Rest, 1994, cited in Lincoln et al.2011)

$\checkmark$ Moral judgment: That refers to how we formulate and evaluate which possible solution to the moral issue has moral justification

$\checkmark$ Moral motivation (moral intention): Refers to the intention to choose the moral decision over another solution representing a different value. "For example, an individual may recognize two solutions to a dilemma, one that results in an increase of personal power and one that is morally right. In this instance, moral motivation is the individual's intention to choose the value of morality over the value of power" (Lincoln et al., 2011, p.57).

$\checkmark$ Moral courage (moral action): Is the individual's action in the situation and involves courage, determination and the ability to follow through with the moral decision

From the previous chapters we can easily understand that the company in question has to take an ethical decision. This decision is not an easy one as it has to undertake some important risks and not to follow calculus. Instead, the company needs to act ethically something which involves all the four components mentioned above. Under this prism, ethics can be a motive for the decision making process only when the company in question will adopt these four steps and especially the last one which will be the way to implement such a decision.

But can uncertainty become a motive? According to Shen et al. (2015), uncertain rewards can act as a motive to marketers. The same goes to companies. In our case, uncertainty is the motive for a company, to relocate. It is obvious from the above that such motivation can also be a decisive paragon in decision making in cases like this one.

According to Menger (1967), there are two important paragons which we need to consider during the decision making process, the strength of our motive and the probability of achieving our aim. In our case, the motive is very strong, although it comes from a negative factor (uncertainty), while the probability of achieving the company's aim is not that high. The important thing is that if motivation is high, the second paragon is not equally important. This can also be very important from the point of view of a positive motive which is the ethical part of the decision process which involves the local society. Also, we should never forget that the probability of achieving one's aim is not always so objective. The determination paragon can overcome all the negative probabilities.

The author concludes that two paragons are the most important in decision making, the strength of our motive and the probability of achieving our aim. The second element is different than the first, unless we can explicitly include uncertainty in the idea of motivation.

\section{DECIDING UNDER VAST PRESSURE}

As Drucker said "Making good decisions is a critical skill at every level". The question here is, when we come to decision making in company's level, the people responsible for the decision are only based on facts or also on emotional factors which spring from the potential economic pressure due to the company's overall financial position and the way they are emotionally involved with the company and the local society in which they participate vividly?

Giora K (1987), contacted an experiment involving 101 graduated students (59 women and 42 men), aged between 20 and 40 . They were requested to solve some decision problems using an interactive computer paradigm, while they were exposed to controllable, uncontrollable stress and no stress at all. The results indicated that those who were exposed to stress (controllable or uncontrollable), showed a significantly stronger tendency to offer solutions before all the available alternatives have been considered and to scan their alternatives in a non- systematic way than the other who weren't exposed to stress at all. 
So, if we agree that managers who are responsible for decision making are just humans who are, logically enough, influenced by their environment, then the above mentioned example means that the decision making can be influenced by stress, something which can lead to wrong circumstances' evaluation thus wrong decision making.

\section{CONCLUSIONS}

In this paper, the author tried to depict one decision problem which is major nowadays in Greece's contemporary market. The market saturation, which in combination with the economic recession can lead companies to relocate in neighbouring countries in order to find less taxes and lower labour cost.

The author tried to represent that decision making process under the depiction of a decision tree, which although is not a panacea, it can serve us very well, and in fact is the way the author operates in his every- day life decision making problems.

The author mainly followed the SSD approach of the decision theory. Several other issues were examined accordingly to the utility approach which indicates that there is a discrepancy between mathematical expectations and the utility of the outcome. The author decided to follow such direction because he strongly believes that people under vast psychological, emotional and economical pressure would decide, in a large degree, intuitively.

The decision making process, especially in such stressful situations, where the company's existence is at stake, usually is not a matter of calculus but mainly a matter of intuition or utility as we can say, especially when the emotional paragon is strongly involved as this is the case with the results of the decision will vastly influence the local society.

According to Kanter (2008) "When giants transform themselves from impersonal machines into human communities, they can transform the world". When companies stop being impersonal machines only trying to accumulate wealth no matter what the cost is for the society, and transform themselves into living parts of the society in which they contribute in several ways, i.e. donations, community actions, building or contribute in building substantial infrastructure for the wellbeing of the local society etc. they can really alter the world because they have the power to do it. Firstly on a local scale but as this will expand as a chain reaction it will spread in no time to the whole world. This humanitarian approach is how companies and societies should operate. Companies are parts of the societies and in that way they need to operate.

\section{REFERENCES}

[1] Apostolakis E. George, 2004. "How useful is quantitative risk assessment?". Risk Analysis, Vol.24 (3), pp. 515-520.

[2] Best R., 2014. Market- based Management. $6^{\text {th }}$ ed. USA, Pearson Education Ltd.

[3] Courtney H.; Kirkland J., Viguerie P., 1997. Strategy under uncertainty. HBR. Vol.75 (6), pp.66-79.

[4] Fischhoff B.; Watson S.; Hope Chris, 1984. "Defining Risk”. Springer. Vol 17(2), pp.123-139.

[5] Investopedia, n.d. Small and Midsize Enterprises- SMEs. [online]. Available at:< http://www.investopedia.com/terms/s/smallandmidsizeenterprises.asp> [Accessed 23 September 2016].

[6] Giora K., 1987. "Decision making under stress: Scanning of alternatives under controllable and uncontrollable threats". Journal of Personality and Social Psychology, Vol 52(3), pp. 639-644.

[7] Kanter R.M., 2008. "Transforming Giants" HBR [online]. Available at: < https://hbr.org/2008/01/transforming-giants> [Accessed 24 September 2016].

[8] Karaoulanis A.; Monfort F., 2015. "A comparative study of women in top managerial positions between Greece and the UK" MBA Thesis. Blekinge: BTH

[9] Karaoulanis A., 2016. "The combination of turnaround management, blue ocean strategies and disruptive innovation as tools in guiding companies in overcoming their recession problems and develop a long- term healthy economic performance". Journal of Social Sciences Research. Vol 10(1), pp. 1962-1967.

[10] Karaoulanis A., 2015 "Turnaround management and blue oceans strategy implementation" Journal of Social Sciences Research. Vol 9(3), pp. 1867-1870.

[11] Kochenderfer M.J., 2015. "Decision making under uncertainty. Theory and applications". Massachusetts, The MIT Press.

[12] Lincoln S.; Holmes A., 2011. "Ethical Decision Making: A Process Influenced by Moral Intensity" Journal of Healthcare, Science and the Humanities. Vol 1 (1), 2011.

[13] Magee J.F., 1994. "Decision trees for decision making" HBR [online]. Available at: https://hbr.org/1964/07/decisiontrees-for-decision-making [Accessed 20 September 2016].

[14] Malmnas Per Erik and Paulsson Andreas, 2016. Decision problems and ways of handling them [pdf]. Version $\begin{array}{lll}\text { 07.08.2016. Available } & \text { at: } & < \\ \text { https://ilearn2.dsv.su.se/pluginfile.php/88134/mod resource/content/6/MalmnasPaulsson2016.pdf. [Accessed } 29 \text { August }\end{array}$ 2016]

[15] Menger, K., 1967. The Role of Uncertainty in Economics. In M. Shubik, ed. 1967. Essays in Mathematical Economics, in Honor of Oskar Morgenstern. Princeton, N.J.: Princeton University Press 
[16] Peters O., 2011. "The time resolution of the St Petersburg paradox" The royal society publishing. Org [online]. Available at: < http://rsta.royalsocietypublishing.org/content/369/1956/4913> [Accessed 18 September 2016].

[17] Shen L.; Fishbach A.; Hsee C., 2015. "The Motivating-Uncertainty Effect: Uncertainty Increases Resource Investment in the Process of Reward Pursuit". Journal of Consumer Research, Inc. Vol.41, pp. 00-00(not final).

[18] Wernerfelt B; Kamani A., 1987. Research notes and communications. Competitive strategy under uncertainty. Strategic management journal. Vol.8, pp. 187-194.

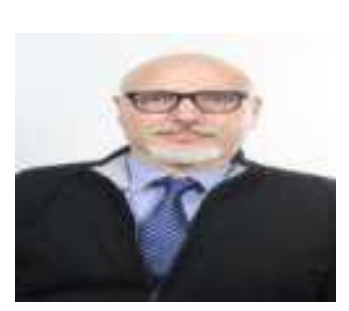

Andreas Karaoulanis, MBA, MsEng is currently working in the banking sector in Greece. He has a MBA degree in Industrial Management and Economics form Blekinge Institute of Technology

Sweden and a MSc in Engineering from Aristotle University of Thessaloniki . He is currently enrolling on a MSc in decision support and risk analysis in Stockholm University Sweden. He is very experienced after 25 years of working in several industries like engineering, banking, retail and consulting. He is an ESL teacher and a Linked In blogger with many managerial posts. 